\title{
ONTWIKKELINGSBEHOEFTES EN ADMINISTRASIE
}

\begin{abstract}
With a colonial history of paternalistic administration behind it, the Third World burocracies have suddenly been given the task to play a development role apart from their administrative functions.
\end{abstract}

In several countries (inter alia Malawi, Botswana and Swaziland) variations in development committees and boards have been experimented with, with a varying degree of success. The ideal institution for interaction between government and population must yet be created and will probably differ from country to country. A 'development administration-doctrine' is coming into being, but many shortcomings must still be dealt with before an ideal approach will emerge.

\section{Inleiding}

'The new, emerging African society wanted to put its stamp on government administration but one committed to development.' (Hyden, 1975, p. 1)

In hierdie woorde lê die probleem en die uitdaging waarvoor die ontwikkelingsadministrateur te staan kom. Na die Tweede Wêreldoorlog het dekolonisasie teen 'n byna koorsagtige spoed geskied. Oornag het Afrika polities onafhanklik geword en is wetgewende en uitvoerende gesag van die koloniale ryke na die kolonies oorgedra.

'n Gebied kan nie regeer word sonder 'n vorm van burokrasie of administratiewe instelling nie. As algemene reël kan dit gestel word dat alle kolonies ' $n$ vorm van burokrasie tydens onafhanklikheid gehad het. Uit die aard van die saak was die instellings geskoei op dié van die moederland. Dit kan ook gestel word dat ontwikkeling van die Derde Wêreld wat met die dekolonisasie ' $n$ aanvang geneem het, hoofsaaklik Westers georiënteerd was. Die modernisasie benadering tot ontwikkeling het sy beslag na die Tweede Wêreldoorlog onder Westerse (veral Amerikaanse) geesteswetenskaplikes verkiry. Hierdie benadering is hoofsaaklik op ekonomiese groei gerig. Milton J. Esman 'n eksponent van die benadering, omskryf ontwikkeling as dat dit betrekking het op regeringsaktiwiteite wat ekonomiese groei aanmoedig, menslike en organisatoriese bekwaamheid versterk en gelykheid van geleenthede, inkomste en mag bevorder. (Esman, 1974, p. 3)

Vanuit die Derde Wêreld het reaksie teen die Westerse benadering gekulmineer in die 'depen- dencia' of afhanklikheidsteorie. Die Derde Wêreld se ekonomiese afhanklikheid van die 'Westerse kapitalisme' vorm 'n belangrike punt van kritiek in die teorie. Afhanklikheidsteoretici is dan ook meer beskeie by die stel van ontwikkelingsbehoeftes. Denis Goulet formuleer die behoeftes as volg:

'Third World nations are increasingly frustrated by their vulnerability in the face of strong partners. In simple terms, their quest for development is symbolized by two objectives: bread plus dignity' (1974, pp. 32-33)

Watter teoretiese grondslag die stel van ontwikkelingsbehoeftes ookal bepaal, moet daar 'n instelling wees wat in die behoeftes kan voorsien. Tereg stel Merle Fainsod dit dat daar meer as 'n ontwikkelingsplan nodig is om in die behoeftes te voorsien. 'n Span opgeleide administrateurs, toegerus met kennis en hulpbronne is nodig om beleid en planne uit te voer. (Fainsod, 1963, p. 1)

Die tuiste van so 'n span opgeleide administrateurs is in die burokrasie. Uit die ontwikkelingsbehoeftes in die Derde Wêreld is dit egter duidelik dat die Westerse beskouing van burokrasie as die uitvoerder van wet en orde nie sondermeer oorgeplant kan word nie.

\section{Die Westerse burokrasie}

Die konteks waarin ontwikkeling van die burokrasie in die Weste geskied het, het heelwat verskil van die konteks in die minderontwikkelde wêreld wat na WO II polities onafhanklik geword het. Die volgende drie kenmerke van die Westerse konteks kan onderskei word: 
a) 'n Redelike stabiele politieke basis. Regerings- en politieke strukture het bestaan en 'n nasionale gevoel het mense en groepe verbind. Regeringsprosesse was wettig, het gesag afgedwing en was redelik doeltreffend.

b) Entrepreneurskap en organisasievermoë binne die gemeenskap was voldoende om ontwikkelingsprojekte te inisieer. Hoewel hoofsaaklik ekonomies, is ook maatskaplike en onderwysprojekte op hierdie wyse begin. Die staat en burokrasie is dus in 'n groot mate van bogenoemde 'Sosiale' las, wat finansies en organisasie uitsluit, onthef.

c) Gemeenskapseise aan die staatsdiens was matig, en binne die regering se vermoë om te hanteer. Slegs 'n klein persentasie van die ekonomiese en opgeleide mannekrag is deur die regering gebruik. (Esman, 1974, p. 4).

Die geleidelike ('Gradual') politieke ontwikkelings wat lande soos Brittanje en die VSA beleef het, het ook ' $n$ invloed op hulle administratiewe instellings se ontwikkeling getoon. Die belangrikste gevolg van die geleidelike politieke ontwikkeling op administratiewe ontwikkeling was dat:

' . . . the administrative system also was able to take shape feature by feature in a way that reflected the political changes and was consonant with them.' (Heady, 1979, p. 198).

Uit die lang geskiedenis van politieke ontwikkeling het 'n Westerse burokrasie ontwikkel wat bepaalde kenmerke het. Omdat die Westerse burokrasie as modelle vir hul voormalige kolonies gedien het en omdat Westerse ontwikkelingsmodelle op dié bekende lees geskoei was is dit nodig om kortliks na hul belangrikste kenmerke te kyk.

i. Die regeringsorganisasie is hoogs gedifferensieerd en funksioneel en politieke rolle word op grond van bekwaamheid toegewys. Dit het tot gevolg ' $n$ hoë mate van interne spesialisasie met bevoegdheid en meriete as norm vir rekrutering in die burokrasie.

ii. Politieke besluitnemingsprosedures is rasioneel en sekulêr. Die rol van tradisionele elites en waardes is verswak, wat weerspieël word in 'n sekulêre en onpersoonlike wetstelsel.

iii. Die omvang en trefkrag van politieke en administratiewe aktiwiteite is groot en dring feitlik alle lewensfere binne.

iv. Daar bestaan 'n hoë mate van korrelasie tussen politieke mag en wettigheid.

v. Populêre belangstelling en betrokkenheid by die politieke stelsel is groot hoewel dit nie noodwendig die bevolking se aktiewe deelname aan politieke besluitneming beteken nie. (Heady, 1979, p. 168)

Teen die agtergrond moet die kenmerke van die ideaal-tipiese burokrasie, soos beskryf deur Max Weber, beskou word. Weber het die kapitalistiese ekonomiese stelsel in gedagte gehad wat hy wou verklaar aan die hand van ekonomiese, politieke en sosiokulturele ontwikkeling. (Damle, 1979, p. 11). Die kenmerke van Weber se burokrasie is die volgende:

i. Personeel geniet persoonlike vryheid en is ondergeskik aan gesag in soverre hul onpersoonlike amptelike pligte betref.

ii. 'n Hiërargiese kantoorstelsel bestaan.

iii. Elke kantoor se bevoegdheid word wetlik bepaal.

iv. Poste word gevul deur vrye en kontraktuele verhoudings.

v. Aanstellings geskied op grond van tegniese kwalifikasies en nie deur verkiesing nie.

vi. Vergoeding geskied deur 'n vasgestelde salaris. Amptenare kan in enkele en uitsonderlike gevalle afgedank word maar dit staan hulle vry om enige tyd en vrywillig te bedank.

vii. Die pos in die burokrasie is die bekleër daarvan se enigste beroep.

viii. Die burokrasie bied 'n loopbaan ('career') waarin bevordering op grond van senioriteit of prestasie geskied.

ix. Amptelike werk is ten volle geskei van die eienaarskap van administratiewe hulpmiddele en bronne.

$x$. Die amptenaar is onderworpe aan streng dissipline en beheer oor die uitvoering van sy taak. (soos aangehaal in Damle, 1979, pp. 10-11). 
Uit die voorafgaande kom 'n prentjie na vore van 'n streng en onpersoonlike burokrasie wat die sentrale regering se beleid afsydig maar doeltreffend uitvoer. Die Weberiaanse model word nêrens in 'n suiwere vorm aangetref nie maar dit kan tog gestel word dat die Westerse burokrasie baie kenmerke van die voorafgaande beskrywings bevat. Teen die agtergrond moet die burokrasie in die Derde Wêreld beskou word.

\section{Die koloniale erflating}

Hoewel die reg op vryheid en selfontwikkeling van die kolonies erken is (Lugard, 1970, p. 88) het die koloniale moondhede tog 'n paternalistiese houding tov die administrasie van hul kolonies aangeneem. Lugard stel dit as volg (1970, p. 88).

'Such liberty and self-development can be best secured to the native population by leaving them free to manage their own affairs through their own rulers, ... under die guidance of the British staff, and subject to the laws and policy of the administration.'

Dus vry om hul eie sake te hanteer solank daar net binne die 'laws and policy of the administration' gebly word en die leiding van die Britse amptenare gevolg word: Die paternalistiese houding is versterk deur die amptenare wat as 'n klein groepie uit die moederland ' $n$ besondere status aan hulself toegereken het. Die groepsgees en sosiale kode wat die 'klub' gestel het was verantwoordelik vir die stel van standaarde wat, in sommige gevalle, nutteloos in die onafhanklike state sou wees. Samehangend hiermee is die feit dat kolonies regeer is vanuit die moederland - wette en regulasies is in Londen, Parys en Berlyn gemaak. Betekenisvolle deelname aan die proses van besluitneming het slegs op ' $n$ beperkte skaal voorgekom met die gevolg dat plaaslike leiers eensklaps (na onafhanklikheid) met die regte en ook verpligtinge van die regeringstaak kennis gemaak het.

Die burokrasie is na onafhanklikheid met ' $n$ stel algemene reëls en regulasies uit die koloniale tydperk gelaat wat hulle of ondoeltreffend gevind het of net nie wou toepas nie.

'Feeling that the General Orders and regulations were merely a European invention designed to keep a tight grip on the population ... people tended to deride them.' (Gardiner, 1975, p. 14).
Die probleem met die koloniale reëls en regulasies was dat dit sentraal (in die moederland) ontwerp was en dan universeel en sonder inagneming van plaaslike toestande, gebruike en tradisies toegepas is.

Hierdie is enkele aspekte van die probleme wat burokrasieë van onafhanklike Derde Wêreldlande uit die koloniale tydperk geërf het. Teen die agtergrond en met die relatief minderontwikkeldheid van Derde Wêreldlande tydens onafhanklikheid in gedagte, kan die eise wat aan die burokrasie gestel word van nader beskou word.

Eise aan die regering vir openbare dienste is baie groter as die administratiewe en ekonomiese bekwaamheid van minderontwikkelde lande. Hierdie eise is gemobiliseer as gevolg van na-onafhanklikheidspolitiek (beloftes van gelyke betaling, onderwys vir almal, ens.), die invloed van moderne kommunikasie en buitelandse hulpverlening (en organisasies). Eise ten opsigte van infrastruktuur, landbou en industrieë, onderwys, behuising, arbeid en welsyn word gemaak.

Hierdie eise bring nuwe verantwoordelikhede vir die regering en die burokrasie mee, naamlik:

(i) Ekonomiese en ontwikkelingsbeplanning. Vir die uitvoering van groot projekte soos paaie, damme en kragvoorsiening is Westerse tegniese en administratiewe kennis voldoende en 'oorplaasbaar'. Die probleem lê egter by die bepaling van ontwikkelingsbehoeftes en die beplanning van ontwikkelingsprojekte.

(ii) Burokrate moes as 'agente vir verandering' optree in byvoorbeeld die gebruik van verbeterde boerdery-metodes, waardeur hulle in konflik kom met tradisionele gemeenskappe/waardes.

Deur bv 'n veeverbeteringskema met wetlike maatreëls op 'n gemeenskap wat daarteen gekant is af te dwing, sal die amptenaar toesien dat die wet uitgevoer word maar sal ontwikkeling ongetwyfeld daaronder lei. Die burokraat se rol behoort dus te verander van wetstoepasser na gemeenskapsontwikkelaar. Die amptenaar in die Derde Wêreld het dus 'n veeleisende en omvangryke taak.

(iii) Pogings om ontwikkeling aan te moedig, skep soms spanning tussen groepe etnies, ekonomies, godsdienstig, ens. Regeringsoptrede moet dus ook rekening hou met 
die wegkanalisering (of die voorkoming) van bogenoemde spanning.

(iv) Spesialisorganisasies wat noodsaaklik is vir innovasies moet dikwels deur die staat tot stand gebring en beman word. Sodanige organisasies sluit onder ander landbouskole, onderwyskolleges en gesondheidsklinieke in (Esman, 1974, pp. 11-12).

In minderontwikkelde lande is entrepreneurs-, bestuurs- en professionele bekwaamhede uiters skaars. Vrywillige organisasies vir die verskaffing van sosiale en ekonomiese hulp (Rooikruis, ens) is dikwels nie in staat om ' $n$ bydrae op nasionale vlak te lewer nie. Waar sodanige organisasies wel bestaan is hul aktiwiteite in hoofsaak gerig op die kleiner familie- of stameenheid. Dié grootste persentasie opgeleide mense is betrokke by regeringsinstellings, met die gevolg dat daar buite die staatsdiens nie 'n noemenswaardige bron van opgeleide mannekrag bestaan nie. Waar so 'n bron wel bestaan, word dit in baie gevalle deur 'n etniese groep oorheers en daarom, as dit nie deur dieselfde groep as die regering gevorm word nie, deur die regerende elite gewantrou.

In Kenia en Tanzanië moes die bewindhebbende partye daardie poel van ondernemers voorsien en die rol van vrywillige organisasies vervul. Hoewel die twee partye ideologies verskil, moes die 'partyman' in beide gevalle met sy gemeenskap skakel, hulle behoeftes bepaal en innovasies aanvoer. In die sosialistiese Tanzanië, waar 'villagization' (ujamaa) staatsbeleid is, is die regering, burokrasie en party baie nouer verbonde aan mekaar as in Kenia waar die party ondergeskik aan die burokrasie is. (Africa, 1970, p. 62).

In beide lande (soos in baie Derde Wêreldlande) beklee die burokrasie ' $n$ toonaangewende rol in die ontwikkelingstryd. Dit kan ook nie anders nie: die burokrasie is die belangrikste werkgewer en daarom die grootste fokuspunt van opgeleide mannekrag in die minderontwikkelde wêreld. Die mensepotensiaal wat in die burokrasie saamgetrek is moet noodwendig ' $n$ leidende rol in die ontwikkelingstryd speel.

\section{Die Derde-Wêreld burokrasie}

Vanuit die Derde Wêreld word daar gevra vir 'n algehele vernuwing van die burokrasie. Op feitlik alle lewensterreine word nuwe eise aan die burokrasie gestel. Die koloniale burokrasie moes skielik in 'n dinamiese inheemse burokrasie verander wat ' $n$ ontwikkelingsgerigte benadering moes volg. A. L. Adu stel dit as volg:

'the old colonial administrations and technical departments were concerned with such matters as maintenance of law and order (and) local administration... There were no 5 to 10 year development plans, no major policies or industrialization ... ' (Adu, 1965, p. 226).

Volgens Adu is die doel van hervorming op dié terrein dan om masjinerie daar te stel wat die administratiewe funksie volgens die eise van moderne regering kan uitvoer (Adu, 1975, p. 26).

Bogenoemde kan as tegniese vereistes beskou word. Bepaalde vaardighede, kennis en instellings word benodig om die administrasie te laat vlot. Die ontwikkelingsrol van burokrasieë veroorsaak egter 'addisionele' eise - eise om deelname en betrokkenheid deur die bevolking aan die prosesse van administrasie en ontwikkeling. Dit beteken 'grass roots' deelname en 'n nouer kontak tussen bevolking en owerheid. Kommunikasiekanale moet daargestel word waardeur: ' . . . their needs and demands and their problems and ideas can be channelled up to central government and to the leadership' (Mchauru, 1975, p. 79).

Aanpassings in die oorgeërfde administratiewe doktrine is gevolglik 'n noodsaaklikheid. Waar die bevolking geen deelname aan beplanning. en plan-implimentering het nie kan dit tot 'n negatiewe reaksie lei.

Oor die noodsaak vir bevolkingsdeelname aan ontwikkelingsprojekte en die belangrikheid van die burokrasie se rol daarin, is die modernisasieen afhanklikheidsteoretici redelik eensgesind. Hul benaderingsverskille kom by die vraag hoe om die doelwitte te bereik. Esman as verteenwoordiger van die modernisasiebenadering, heg heelwat waarde aan die formele rol van die burokrasie. Hy bepleit wel 'n buigsamer benadering deur die burokrasie - innovasie, eksperimentering, deelname aan die ekonomie, betrokkenheid by kliënte - maar waarsku ook dat: 'This does not mean that the classical norms are irrelevant ... but that a different emphasis is required ... (Esman, 1974, p. 16). Esman bepleit dus 'n aanpassing van die klassieke burokrasie om by die Derde Wêreld se ontwikkelingsbehoeftes aan te pas. Hy gaan egter verder en bepleit die aktiewe konsultasie met en deelname deur kliënte aan die administratiewe proses. 'Clients must be consulted and even 
brought into administrative process.' Clients must be consulted and even brought into administrative roles' (1974, p. 19).

In die beskouing vind Esman aansluiting by Denis Goulet wat sê dat 'administrations must make themselves institutionally vulnerable'. (1974, pp. 37-38) en dat die burokrasie doel moet wees om die bevolking kontrole oor die proses van ontwikkeling te laat verkry. (p. 53). Grondliggend tot Goulet se benadering is die gedagte dat die bewoners van die Derde Wêreld in 'n posisie van afhanklikheid en kwesbaarheid is. Die waardes en kulturele goedere van 'n gemeenskap word vernietig omdat dit as onversoenbaar met 'moderne' eise sou wees - Hul 'wortels' en oorsprong as 't ware afgebreek en tegelykertyd word hulle blootgestel aan 'n (vir hulle) oorweldigende tegnokultuur wat hul kwesbaarheid verhoog. In hierdie klimaat word gemeenskappe dan blootgestel aan dwangmatige burokratiese optrede - verpligte militêre diens, skoolplig, verpligte dra van identiteitsdokumente. Daar moet dus teen gewaak word dat die middel nie die doel word nie: 'administrations exist to serve the administered, not the reverse' (Goulet, 1974, p. 36).

Dit gaan dus nou nie om administrasie van bo nie, maar van die 'grass roots level' af. Ten einde ontwikkeling in die Derde Wêreld te bevorder moet die bevolking se vrywillige deelname aan administrasie verkry word.

\section{5. 'n Nuwe benadering}

Die Franse sosioloog Robert Caillot is ' $n$ voorstander van 'n benadering waarin die gemeenskap, politieke, administratiewe en vrywillige instellings saam plaaslike ontwikkelingsdoelwitte sal bepaal. 'The populace helps define the rules governing the very research being made on its needs and serves as the principal judge of development action taken in its behalf' (Goulet, 1974, p. 46). Die vyf stappe in die deelnameproses wat deur Caillot voorgestel word is kortliks:

i. 'n Kwalitatiewe beskrywing van die deelnemende instellings aan ontwikkeling;

ii. ' $n$ voorstelling van bg instellings se geografiese verspreiding;

iii. analise van die instellings (grootliks gedoen deur die plaaslike gemeenskap); iv. 'n sintese van al die bogenoemde elemente;

v. omskakeling van studiegroepe in aksiegroepe.

Deur studie en aktiewe deelname word die gemeenskap dus betrek by die bepaling van hul behoeftes, deelname aan en implimentering van ontwikkelingsplanne en kan plaaslike ontwikkelingsdeelname sodoende geïnstitusionaliseer word. Goulet beskou Caillot se benadering as 'n 'nie-elitistiese model vir administrateurs' en kom tot die versigtig optimistiese gevolgtrekking dat: 'His formula is a possible model of new administrative behaviour.' (1974, pp. 50-51). In wese is die benadering van Caillot 'n gemeenskapsontwikkeling benadering. Volgens Edwards en Jones is gemeenskapsontwikkeling:

. ... the process in which the people of a community attempt a collaborative effort to promote what they consider to be the well-being of their community.' (1976, p. 138).

Gemeenskapsontwikkeling gaan dus oor die deelname van mense aan besluite om hul eie omstandighede te verbeter en ook deelname aan die uitvoering van daardie besluite.

Die nuwe benadering is met wisselende mate van sukses in verskeie Afrika-state beproef; enkele voorbeelde van ontwikkelingspogings sal ter illustrasie bespreek word.

In 1965-66 het die grootste droogte in 30 jaar Lesotho getref. Hulp is by die 'World Food Program' gevra maar weens vertragings soos dokstakings en administratiewe rom-slomp het die kos voorraad eers die volgende jaar opgedaag. Intussen het die politici en tradisionele leiers kos beloof aan almal wat aan enige 'self-help-projek' werk. Baie projekte is begin, maar die beplanning daarvan was swak en ongekoördineerd.

Nuwe paaie het in erosieslote verander, min mense is in werklikheid beloon en in sommige statte het mense later vergoeding verwag vir enigiets wat hulle gedoen het. Die gevolg: paaie, damme - alles wat deur selfhelp gebou is - het in onbruik geraak. Wie bou 'n pad/dam waarvoor hy self nie gevra het of die nut van in sien nie?

Hierdie voorval in Lesotho was 'n geval waar daar op ' $n$ projek besluit is sonder om die mense in te lig - sonder om informasie by die mense te kry - dus sonder die mense se emosionele 
deelname (Danforth, 1974, pp. 332-337).

In Kenia het die toestand ontstaan dat weens 'n verdeling onder die bevolking die politici al meer van die burokrasie gebruik gemaak het om politieke eenheid in die land te behou. Die leidende rol van KANU is dus deur die burokrasie oorgeneem.

Hierdeur is die burokrasie se rol van die 'klassiek Westerse' model verbreed en speel dit ook 'n belangrike rol in die politiek.

Ontwikkelingsbeplanning en implimetering geskied deur die burokrasie in samewerking met buitelandse vakkundiges. Weens die toedrag van sake is deelname aan die ontwikkelingsbeplanning en die burokratiese proses deur die plaaslike bevolking tot ' $n$ minimum beperk. ' $n$ Verklaring vir die toedrag van sake word gevind in die voormalige President Kenyatta se verklaarde konserwatisme: 'I must warn you not to start by demolishing the whole structure created by the colonial government because of some untried experiment'. Die gevolg is dat kommunikasie tussen die regering en die 'volk' steeds deur die burokrasie geskied eerder as deur die verteenwoordigers in die parlement. Die burokrasie in Kenia vervul dus steeds sy 'klassieke' rol.

Die onbeteuelde gesag van die burokrasie tesame met die sterk elite in Kenia het tot gevolg dat, hoewel Kenia se ekonomie vinnig groei, die kloof tussen die 'haves' en die 'have nots' vinnig verbreed. Die armes en hul stem tel al hoe minder, terwyl die rykes ryker word en hul invloed vergroot.

In Malawi is ' $n$ verbasend suksesvolle basis gelê vir die bevordering van 'self help' en vir publieke deelname aan ontwikkelingsprojekte.

Sedert 1966 is die stelsel van 'District Development Committees' (DDC's) in swang. Onder die $D D C$ was 'n aantal 'area'-aksiegroepe wat elk weer verder verdeel is in ' $n$ aantal 'village'aksiegroepe. Die DDC bespreek ontwikkelingsprobleme en behoeftes op distriksvlak en maak aanbevelings. Die implementering van besluite geskied deur die 'area' en die 'village'aksiegroepe. 'n 'Villager' met 'n bepaalde probleem kan sy 'village'-groep se voorsitter nader wat die probleem verder moet voer. Om as aansporing vir komitees te dien is ' $n$ fonds gestig waaruit projekte (kleineres), wat deur die komitees geïdentifiseer is, gefinansier word. Dit veroorsaak 'n gees van 'vervulling' wat verdere samewerking kan aanmoedig. Wat die stelsel soveel aantrekliker maak, is die feit dat elke komitee volgens elke streek se behoefte en gebruik saamgestel word. Die buigsaamheid van instellings waarvan Esman gepraat het, kom hierin duidelik na vore. (Miller, 1974, pp. ).

\section{Samevatting}

Met 'n koloniale geskiedenis van paternalistiese administrasie agter hulle is Derde Wêreld burokrasieë eensklaps voor die taak gestel om buiten hul administrasie funksie ook 'n ontwikkelingsrol te speel. Dié rol vereis 'n nuwe benadering deur die burokrasie waarin die samewerking en instemming van die geadministreerdes verkry moet word. Die benadering nie-elitisties of gemeenskapsontwikkeling - hou ' $n$ radikale verandering van die Westerse en Weberiaanse modelle in. Die afsydige doeltreffendheid van die Westerse burokrasie moet verander word in 'n warm deelnemende bondgenoot.

Die omstandighede waarin die Derde Wêreld burokrasie moet werk is duidelik - so ook die eise wat hulle moet hanteer. Wat wel nog om 'n oplossing vra is die strukturele aanpassings wat ondergaan moet word om die nuwe omstandighede te hanteer. In verskeie lande (o.a. Malawi, Botswana en Swaziland) is variasies op ontwikkelingskomitees en rade al met wisselende mate van sukses beproef. Die ideale instelling vir interaksie tussen regering en bevolking moet nog geskep word en dié sal waarskynlik van land tot land verskil. Aansluitend hierby is die probleem van die integrasie van plaaslike behoeftes en planne by ' $n$ nasionale benadering wat nog nie bevredigend opgelos is nie.

'n 'Ontwikkelingsadministrasie-doktrine' is besig om vorm te kry, maar baie leemtes moet nog gevul word voor die ideale benadering die lig sal sien.

\section{Slotgedagte}

Die ingeligte leser sal opmerk dat hierdie artikel 'n aantal temas omvat wat om diepgaande navorsing roep. Sommige hiervan is wel al goed nagevors, veral deur Amerikaanse geesteswetenskaplikes maar in Suid-Afrika met sy onmiskenbare Derde Wêreldverbondenheid lê die veld as 't ware nog braak.

Die doelwit met hierdie artikel was dus om 'n voëlvlugbeeld van die teenstrydighede? tussen 
die Westerse burokratiese model en die behoeftes in die Derde Wêreld burokrasie aan te dui.

* Mnr F. de Beer, BA Hons is verbonde aan UNISA.

\section{Bibliografie}

Adu, A. L. 1965. The civil service in new African states. New York: F. A. Praeger.

Adu, A. L. 1975. The administrator and change. Rweyemanu, A. H. and Hyden, G. A decade of public administration in Africa. Nairobi: East African Literature Bureau. Africa, 1970. No. 57.

Damle, Y. B. 1979: A framework for the study of bureaucracy. Dube, S. C. Public services and social responsibility. New Delhi: Vikas Publishing House.

Danforth, N. 1974: Lesotho: Towards real independence. Morgan, E. P. The administration of change in Africa. New York: Dunellen. Edwards, A. D. \& Jones, D. G. 1976 . Community and community development. The Hague: Mouton \& Co.
Esman, M. J. 1974. Administrative doctrine and developmental needs. Morgan, E. P. The administration of change in Africa. New York: Dunellen.

Fainsud, M. 1963. The structure of development administration. Swerlow, I. Development administration: concepts and problems. New York: Syracuse University Press.

Gardiner, R. K. A. 1975. From colonial rule to local administration. Rweyemanu, A. H. \& Hyden G. A decade of public administration in Africa. Nairobi: East African Literature Bureau.

Goulet, D. 1974. Development administration and structures of vulnerability. Morgan, E. P. The administration of change in Africa. New York Dunellen.

Heady, F. 1979. Public administration; a comparative perspective. New York: Praeger.

Hyden, G. 1975. The changing role of the African administrator. Rweyemanu, A. H. \& Hyden, G. A decade of public administration in Africa. Nairobi: East African Literature Bureau.

Lugard, F. 1970. Principles of Native Administration. Collins, R. O. The history of colonial Africa, 1860-1960. Englewood Cliffs: Prentice Hall. Mchauru, F. T. 1975. The Tanzanian model. Rweyemanu, A. H. \& Hyden, G. A decade of public administration in Africa. Nairobi: East African Literature Bureau. 